$1-1-1996$

\title{
Uniform Bottom Shear Stress and Equilibrium Hyposometry of Intertidal Flats
}

Carl T. Friedrichs

Virginia Institute of Marine Science

Follow this and additional works at: https://scholarworks.wm.edu/vimsbooks

Part of the Oceanography Commons

\section{Recommended Citation}

Friedrichs, Carl T., "Uniform Bottom Shear Stress and Equilibrium Hyposometry of Intertidal Flats" (1996). VIMS Books and Book Chapters. 37.

https://scholarworks.wm.edu/vimsbooks/37

This Book Chapter is brought to you for free and open access by the Virginia Institute of Marine Science at W\&M ScholarWorks. It has been accepted for inclusion in VIMS Books and Book Chapters by an authorized administrator of W\&M ScholarWorks. For more information, please contact scholarworks@wm.edu. 


\title{
24
}

\section{Uniform Bottom Shear Stress and Equilibrium Hyposometry of Intertidal Flats}

\author{
C. T. Friedrichs and D. G. Aubrey
}

\begin{abstract}
Hypsometry is the distribution of horizontal surface area with respect to elevation. Recent observations of tidal flat morphology have correlated convex hypsometry with large tide ranges, long-term accretion and/or low wave activity. Concave hypsometry, in turn, has been correlated with small tide ranges, long-term erosion and/or high wave activity. The present study demonstrates that this empirical variation in tidal flat hypsometry is consistent with a simple morphodynamic model which assumes tidal flats to be at equilibrium if maximum bottom shear stress $(\tau)$ is spatially uniform. Two general cases are considered: (i) dominance of $\tau$ by tidal currents, where $\tau$ is equal to maximum tidally-generated shear stress $\left(\tau_{\mathrm{T}}\right)$, and (ii) dominance by wind waves, where $\tau$ is equal to maximum wave-generated shear stress $\left(\tau_{\mathrm{W}}\right)$. Analytic solutions indicate that a tidal flat which slopes linearly away from a straight shoreline does not produce a uniform distribution of $\tau_{\mathrm{T}}$ or $\tau_{\mathrm{W}}$. If the profile is adjusted until either $\tau_{\mathrm{T}}$ or $\tau_{\mathrm{W}}$ is uniform, then domination by tidal currents favors a convex hypsometry, and domination by wind waves favors a concave hypsometry. Equilibrium profiles are also derived for curved shorelines. Results indicate that an embayed shoreline significantly enhances convexity and a lobate shoreline significantly enhances concavity - so much so that the potential effect of shoreline curvature on equilibrium hypsometry is of the same order as the effect of domination by $\tau_{\mathrm{T}}$ or $\tau_{\mathrm{W}}$.
\end{abstract}




\section{Introduction}

More than half of the world's non-Arctic coastlines are either macrotidal (spring range $>4 \mathrm{~m}$ ) or mesotidal (spring range 2-4 m) (Davies, 1973). The study of equilibrium tidal flat morphology provides insight into the response of meso- and macrotidal coastlines to such external forcings as engineering works, periodic storm activity, and changes in relative sea level. Hypsometry, which measures cumulative horizontal basin area as a function of elevation, usefully represents broad aspects of tidal flat morphology in a concise and quantitative manner (e.g., Boon and Byrne, 1981). Recent observations (Dieckmann et al., 1987; Kirby, 1992) relating characteristic tidal flat hypsometries to tide range, wind wave activity, and longterm accretion or erosion provide a base of empirical data with which to compare equilibrium hypsometries predicted by analytic theory.

Hypsometric analysis, which was formally introduced to geomorphology by Strahler (1952), is the study of the distribution of surface area of a land mass or basin with respect to elevation. Hypsometries are often presented as non-dimensional plots of relative elevation and relative surface area, allowing a comparison of hypsometry between systems having different scales. Strahler found distinctive hypsometries to be related to the erosional maturity of land regions formed in homogeneous strata. Boon (1975) and Boon and Byrne (1981) applied hypsometric analysis to the study of intertidal basins and used the hypsometry of intertidal storage areas to model patterns of asymmetric discharge in tidal channels near Wachapreague, Virginia.

Figure 1, modified from Boon and Byrne (1981), shows examples of basin morphologies and their associated hypsometries. In Figure 1 and throughout this paper, hypsometric plots display the cumulative horizontal basin area below a given contour. It is important to distinguish the hypsometry from the topographic profile, which is a plot of elevation versus horizontal distance along the gradient of the topography. In Figure 1, for example, all three topographies have linear profiles. Along a straight shoreline (Figure 1a) the profile and hypsometry are interchangeable. Along curved shorelines, however, the nonlinear transformation from profile to hypsometry causes a linear profile to produce a nonlinear hypsometry. If the profile is straight and the shoreline is embayed (Figure 1b), then the hypsometry will be convex. If the profile is straight and the shoreline is lobate (Figure 1c), then the hypsometry will be concave. Boon and Byrne (1981) emphasized the sensitivity of tidal flat hypsometry to shoreline curvature.

Recent observations of tidal flat hypsometry have related the form of the hypsometry to other factors including tidal range, exposure to wind wave activity and patterns of long-term accretion or erosion. In a study of tidal basins along the German Bight, Dieckmann et al. (1987) noted that hypsometries tend to be more concave for lower tidal range flats and more convex for higher tidal range flats (Figure 2a). In a study of macrotidal (spring range $>4 \mathrm{~m}$ ) flats around Great Britain, Kirby (1992) related convexity to long-term accretion and concavity to long-term erosion (Figure $2 \mathrm{~b}$ ). At a few of the locations, Kirby in turn related accretion or erosion to protection from or 
(a) STRAIGHT shoreline, LINEAR hypsometry
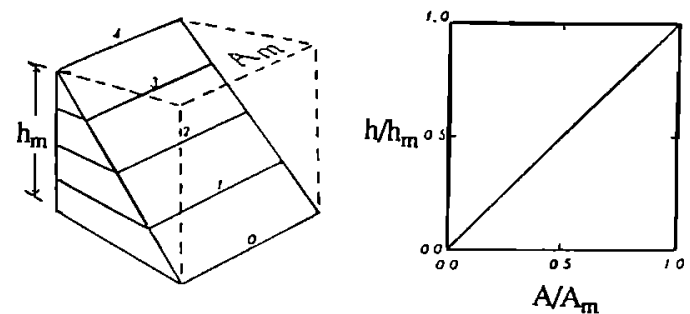

(b) EMBAYED shoreline, CONVEX hypsometry
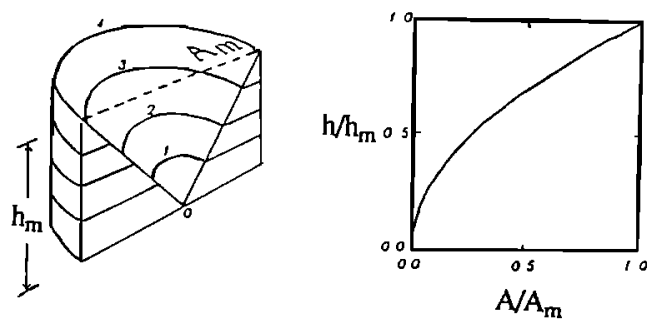

(c) LOBATE shoreline, CONCAVE hypsometry
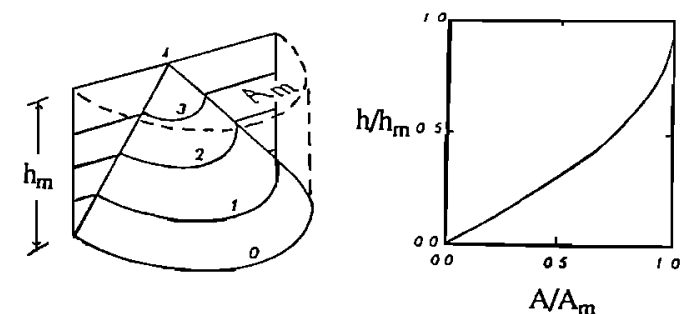

Figure 1. Block diagrams of topographies with linear profiles, along with their associated hypsometries (modified from Boon and Byrne, 1981): (a) Straight shoreline, (b) embayed shoreline, (c) lobate shoreline. $h$ is elevation, $h_{m}$ is maximum elevation, $A$ is horizontal area, and $A_{m}$ is maximum area.

exposure to wind waves. Figure $2 b$ displays the examples of concave and convex hypsometries observed by Kirby along the Severn Estuary. Finally, in a study of sediment exchange off the wide macrotidal flats of western Korea, Wells and Park (1992) described a periodic increase in concavity associated with a seasonal increase in wave activity.

The hypsometric trends described above can be summarized by a qualitative ratio which indicates the relative importance of tidal currents and wind waves:

$$
\begin{array}{ll}
\text { ratio of tidal to wave activity. } & \begin{array}{l}
\text { high } \rightarrow \text { CONVEX hypsometry } \\
\text { low } \rightarrow \text { CONCAVE hypsometry }
\end{array}
\end{array}
$$


This correlation is consistent with observations from the German Bight if spatial variations in tidal range are assumed to be locally more important than spatial variations in wave activity. The same trend describes some of the flats in Great Britain if local variations in wave activity dominate variations in tidal activity. The ratio describes Korean flats, too, if temporal (rather than spatial) variations in wave activity are assumed to be most important.
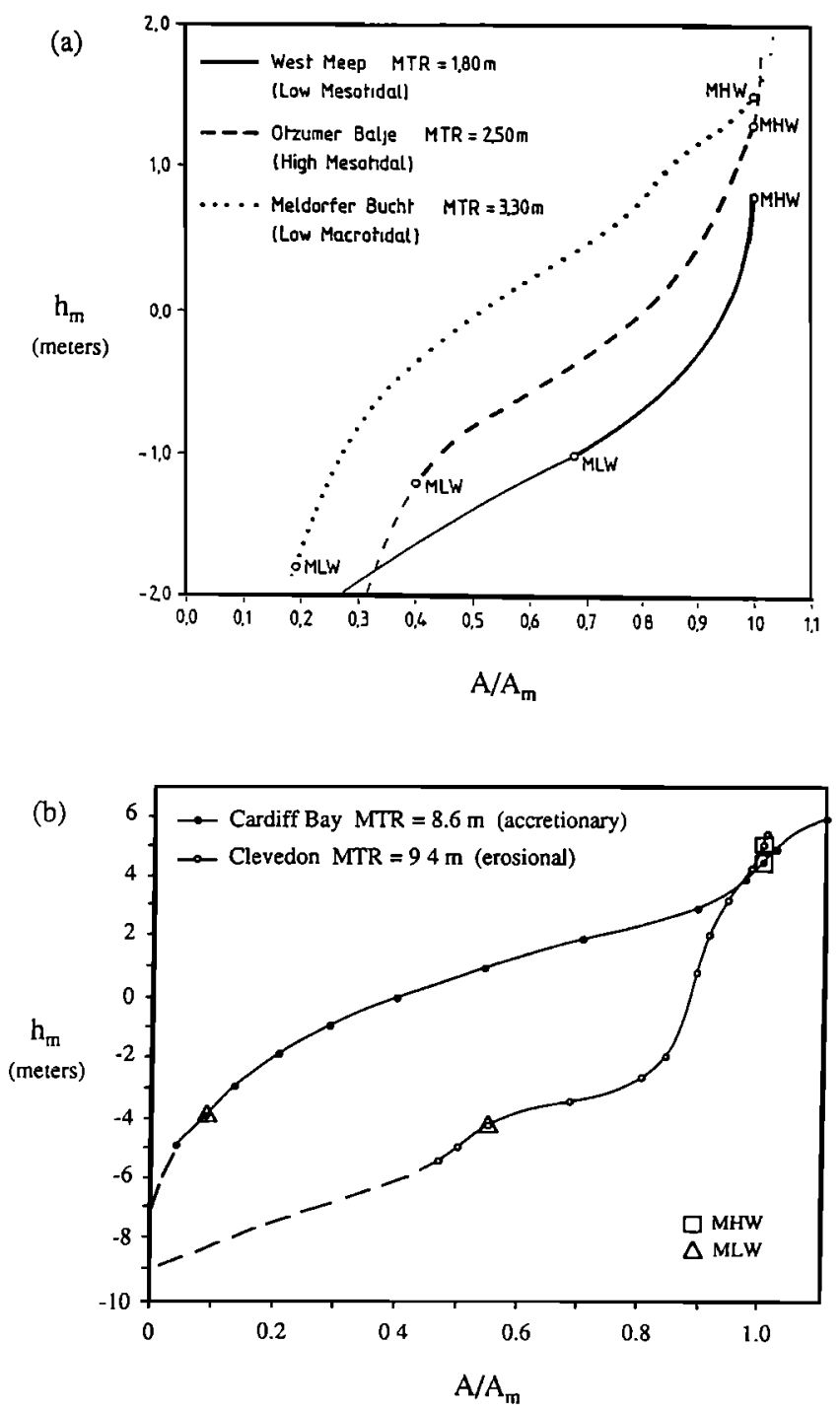

Figure 2. Hypsometries for tidal flats in (a) the German Bight (from Dieckmann et al., 1987) and (b) the Severn Estuary (redrawn from Kirby, 1992). MTR is mean tide range, MHW and MLW are mean high and mean low water. 


\section{Morphodynamic Model}

In this study it is assumed that a stable morphology will result when the distribution of maximum bottom shear stress $(\tau)$ is uniform across a tidal flat. This is a simplification of the more correct formulation that stable morphology results when there is a zero divergence in net sediment transport. Since common formulations for erosion, deposition and net transport are generally expressed as functions of bottom shear stress, often in the form of power relations (e.g., Dyer, 1986), the spatial distribution of bottom shear stress is a useful starting point before attempting to estimate sediment transport directly. Bottom shear stress can be derived from hydrodynamic relations more directly and with a greater degree of confidence.

A deviation of $\tau$ from its mean value across a flat is assumed to cause a local increase or decrease in the rate of sediment dispersal and to cause net erosion or deposition of sediment. This approach focuses on the diffusive nature of sediment transport and does not address the importance of asymmetries in the direction of bottom shear stress. The tidal and wind wave processes considered here are linearized so no asymmetries in direction of $\tau$ are generated. Clearly, asymmetries in $\tau$ can play a morphodynamic role. For example, Friedrichs et al. (1992) suggested that sheet-like intertidal flows tend to be flood dominant, which should enhance deposition. Nonetheless, if $\tau$ is considered to be symmetrical at first-order, then the spatial distribution of its magnitude alone should provide valuable insight into the morphology of stable tidal flats.

For tides in the absence of wind waves or for wind waves in the absence of tides, $\tau$ has been expressed as

$$
\tau=\rho c_{d} U \mathrm{IUI},
$$

where $\rho$ is the fluid density, $c_{d}$ is a dimensionless drag coefficient, and $U$ is maximum depth-averaged velocity during a complete wave or tidal period. The shallow-water approximation allows the decay of wave velocity with depth to be neglected. Bottom stress given by (1) is assumed to be dominated effectively by either waves or currents. Otherwise, wave-current interaction may play a role in determining the net stress field (e.g., Grant and Madsen, 1979). In this study, it is also assumed that $\rho$ and $c_{d}$ are constant in space. Under these conditions, uniform $\tau$ becomes equivalent to uniform $\mathrm{U}$, and equilibrium morphologies can be defined by either $\tau$ or $U$.

\section{Scaling of Problem: Southwest Coast of Korea}

Before beginning a formal derivation of equilibrium hypsometry, it is useful to scale the problem in order to assess its applicability to real tidal flats. The tidal flats along the southwest coast of Korea (Wells et al., 1990; Alexander et al., 1991; Wells and Park, 1992) are chosen as a field example because of their open form and homogeneous composition, attributes which make them particularly amenable to first-order analytic modeling. Unlike many tidal flats bordering the North Sea, the 
Korean flats lack extensive dendritic drainage systems, seaward barriers and landward salt marshes (Alexander et al., 1991). The Korean intertidal sediments are predominantly poorly sorted mud, whereas sediments on flats in the North Sea often show a more well-defined shore-parallel gradation from mud to sand (Klein, 1985).

Along the southwest coast of Korea the mean tide range is about six meters and tidal flats extend locally more than $20 \mathrm{~km}$ out from the coast, although a more typical shore-normal flat length is about $5 \mathrm{~km}$ (Alexander et al., 1991; Wells and Park, 1992). During calm summer weather, tidal currents are presumed to dominate bottom shear stress across the flats. Assuming a sinusoidal particle excursion, maximum tidal current speed is given by $U_{T}=\pi L / T$, where $L$ is the horizontal distance from the low to high water line, and $\mathrm{T}$ is the tidal period. A semi-diurnal period then gives $U_{T}=35 \mathrm{~cm} \mathrm{~s}^{-1}$, which is sufficient to mobilize unconsolidated sediment. Wells et al. (1990) measured maximum current speeds of $\sim 40 \mathrm{~cm} \mathrm{~s}$ s $^{-1}$ across Korean tidal flats, consistent with the above estimate.

During the winter monsoon, Korean flats are exposed to intervals of large ocean swell (Wells and Park, 1992), and wave-generated shear stress is presumed to dominate. The amplitude of orbital velocity for a shallow water wave is given by linear theory to be

$$
\mathrm{U}_{\mathrm{W}}=\frac{\mathrm{H}}{2 \mathrm{~h}}(\mathrm{gh})^{1 / 2}
$$

where $H$ is wave height, $h$ is still water depth and $g$ is the acceleration of gravity. At high tide, a swell of $\mathrm{H}=2 \mathrm{~m}$ at the seaward edge of the flat (where $\mathrm{h} \approx 6 \mathrm{~m}$ ) gives $\mathrm{U}_{\mathrm{W}}=120 \mathrm{~cm} \mathrm{~s}^{-1}$. Since $\tau \sim \mathrm{U}^{2}$, shear stress generated by swell will be an order of magnitude larger than that generated by $\mathrm{U}_{T}$, and $\mathrm{U}_{\mathrm{W}}$ will effectively dominate the net field. Since maximum shear stress generated by waves $\left(\tau_{W}\right)$ has the potential to be much greater than maximum shear stress generated by tides $\left(\tau_{\mathrm{T}}\right)$, one might expect a seasonal transition from tide- to wave-dominated hypsometry to be largely erosional, and a transition from wave- to tide-dominated hypsometry to be largely depositional.

In the following sections, $U$ is used as a proxy for $\tau$ in deriving equilibrium flat morphologies. Under tidal currents, conservation of mass is used to determine the distribution of $\mathrm{U}_{\mathrm{T}}$, whereas under wind waves, conservation of energy is used to determine the distribution of $U_{W}$. In each section, $U$ is first solved for a flat sloping linearly away from a straight shoreline. Profiles and hypsometries which result in a uniform distribution of $U$ at equilibrium are then derived for both straight and curved shorelines. The uniqueness of the resulting equilibrium profiles and hypsometries will not be proven. The goal here is merely a description of simple profile forms across which $U_{\mathrm{T}}$ and $\tau_{\mathrm{T}}$ are constant in space.

\section{Tidal Currents}

If the tidal excursion over the flat is much shorter than the tidal wave length, then it is reasonable to assume tidal elevation $(\eta)$ pumps up and down uniformly across the tidal flat. Phase lags generated by momentum can contribute to velocity 
asymmetries over tidal flats (Friedrichs et al., 1992). However a kinematic approach is useful at first order when examining only the magnitude of tidal velocity. In the past, kinematic approaches have been used successfully in the study of velocity distributions along short channels in tidal marshes (Boon, 1975; Pethick, 1980).

The governing equation applied to tidal currents in the absence of wind waves is simply conservation of mass:

$$
\frac{d \eta(t)}{d t}+\frac{\partial}{\partial x}\left\{h(x, t) u_{T}(x, t)\right\}=0,
$$

where $h$ is local depth, and $u_{T}$ is tidal velocity. Equation (3) also assumes tidal flow to be entirely one-dimensional, neglecting the role played by intertidal channels in concentrating the flow of water across the flats. Nonetheless, flow over tidal flats is often sheet-like, especially during the flood, even in the presence of intertidal channels (Wells and Park, 1992). Although one-dimensional, (3) does not require tidal currents to be perpendicular to the contours. Equation (3) only requires currents to flow at a constant angle to the bathymetry.

Integrating (3) to solve for $\mathrm{u}_{\mathrm{T}}$ gives

$$
u_{T}(x, t)=\frac{x_{f}(t)-x}{h(x, t)} \frac{d \eta(t)}{d t},
$$

where $x_{f}(t)$ is the boundary between the wetted and exposed portions of the flat, hereafter termed the tidal front (Figure 3). Channel depth is defined in terms of its time and space-dependent components:

$$
\mathbf{h}(\mathbf{x}, \mathbf{t})=\eta(\mathbf{t})-\mathbf{Z}(\mathbf{x}),
$$

where $Z(x)$ is the local elevation of the tidal flat profile. Equations (4) and (5) hold for any flat lacking along-shore variations. If $\eta(t)$ and $Z(x)$ are specified, then $h(x, t), x_{f}(t)$ may be calculated, and a solution for $u_{T}$ may be found from (4). Finally $\mathrm{U}_{\mathrm{T}}(\mathrm{x})$ is defined as the maximum value reached by $u_{\mathrm{T}}$ at each point in $\mathrm{x}$ during the tidal cycle.

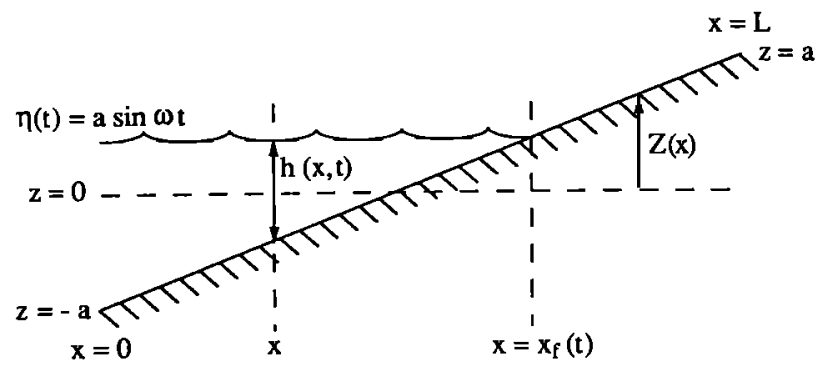

Figure 3. Schematic side view of a linearly sloping flat along a straight shoreline which is dominated by tidal currents. $h$ is tidal elevation, $h$ is local depth, $x_{f}$ is the position of the tidal front, $\mathrm{Z}$ is the elevation of the profile. 


\section{Straight Shoreline, Linear Profile}

Figure 3 displays a linearly sloping tidal flat with a distance $L$ from the low to high water line. The tidal flat profile is given by

$$
Z(x)=\mathbf{a}(2 \mathrm{x} / \mathrm{L}-1)
$$

where $x=0$ at the low water line, and $Z=0$ at $x=L / 2$. For a linear flat, evaluation of (4) is particularly straightforward. If the gradient of the flat is constant, then $\left(x_{f}\right.$ $\mathrm{x}) / \mathrm{h}=\mathrm{L} / 2 \mathrm{a}$, and, with $\eta=\mathrm{a} \sin \omega \mathrm{t}$,

$$
u_{T}(t)=\frac{L}{2 a} \cos \omega t=\frac{L \omega}{2}\left(1-\frac{\eta^{2}}{a^{2}}\right)^{1 / 2} .
$$

From (7) it is clear that maximum tidal velocity will occur when $\eta^{2}$ is at a minimum. For $x \leq L / 2, \eta^{2}$ is at a minimum when $\eta=0$. Thus

$$
\mathrm{U}_{\mathrm{T}}=\mathrm{L} \omega / 2 \text { for } \mathrm{x} \leq \mathrm{L} / 2 \text {, }
$$

and maximum tidal velocity occurs at mid-tide. For $x>L / 2$, however, the smallest value of $\eta$ which maintains water at $x$ is (asymptotically) $\eta=Z$. So,

$$
\mathrm{U}_{\mathrm{T}}(\mathrm{x})=\frac{\mathrm{L} \omega}{2}\left(1-\frac{\mathrm{Z}(\mathrm{x})^{2}}{\mathrm{a}^{2}}\right)^{1 / 2}=\mathrm{L} \omega\left(\frac{\mathrm{x}}{\mathrm{L}}-\frac{\mathrm{x}^{2}}{\mathrm{~L}^{2}}\right)^{1 / 2} \text { for } \mathrm{x}>\mathrm{L} / 2 \text {, }
$$

and maximum tidal velocity occurs at the tidal front. Thus (9) may be alternately expressed for $x>L / 2$ as

$$
U_{T}(x)=\frac{d x_{f}}{d t} \text { when } \quad x=x_{f}>L / 2
$$

Note that (8) - (9) indicate that $U_{T}$ is independent of tidal amplitude.

Figure 4 shows $U_{\mathrm{T}} / \mathrm{U}_{\mathrm{T}_{0}}$ as a function of $\mathrm{x} / \mathrm{L}$ across a linearly sloping flat, where $\mathrm{UT}_{0}$ $=U_{T}(x=0)$. For $x / L \leq 1 / 2, U_{T}$ is constant, suggesting that (in the absence of wind waves) a linear profile is at morphologic equilibrium over the seaward half of the flat. If values are chosen appropriate to the southwest coast of Korea $\left(M_{2}\right.$ tide, $L=5$ $\mathrm{km}$ ) then $\mathrm{UT}_{0} \approx 35 \mathrm{~cm} \mathrm{~s}^{-1}$, which is large enough to mobilize sediment. If the water flows at an angle to the shore, $U_{T_{0}}$ is potentially higher. For $x / L>1 / 2$, however, there is a dramatic decrease in $U_{T}$ as $x / L$ approaches 1 . Thus according to the morphodynamic model applied in this study, a linearly sloping flat with a stress field dominated by tidal currents alone is not at equilibrium for $x / L>1 / 2$. Greater deposition (or less erosion) should occur on the landward half of the flat until $U_{T}$ and $\tau_{\mathrm{T}}$ become nearly uniform across the entire flat. 


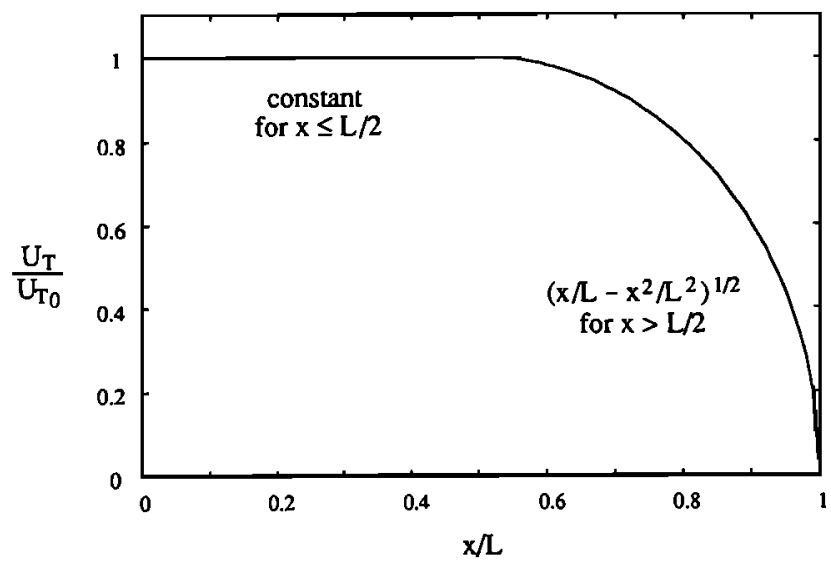

Figure 4. Maximum tidal velocity as a function of distance across a flat which slopes linearly away from a straight shoreline.

\section{Straight Shoreline, Equilibrium Profile}

A tidal flat profile is now derived which results in a uniform distribution of $U_{T}$ across the entire flat. Figure 5 displays a profile which is linear for $\mathrm{x} \leq \mathrm{L}^{*}$ and non-linear for $x>L^{*}$. $L^{*}$ is defined such that $Z=0$ at $x=L^{*}$. The elevation of the lower tidal flat profile is given by

$$
Z-(x)=a\left(x / L^{*}-1\right) \text { for } x \leq L^{*},
$$

where $L^{*}$ is also the length of the lower profile. From the linear profile case (see above) it follows that for $\mathrm{x} \leq \mathrm{L}^{*}, \mathrm{u}_{\mathrm{T}}=\mathrm{L}^{*} \omega$ at mid-tide and, therefore, $\mathrm{U}_{\mathrm{T}}$ is at least as large as $\mathrm{L}^{*} \omega$. Also from the preceding section, it seems reasonable to assume that for $x>L^{*}, U_{T}$ occurs at the tidal front. The next step is therefore to determine what $Z$ is required to give

$$
\frac{d x_{f}}{d t}=L * \omega \text { for } x>L^{*}
$$

Following a particle at the tidal front:

$$
\frac{d x_{f}}{d \eta}=\frac{d x_{f}}{d t} \frac{d t}{d \eta},
$$

where $d t / d \eta$ is found from $t=\omega^{-1} \arcsin (\eta / a)$. Utilizing (12) and integrating (13) then yields

$$
x_{f}-L^{*}=L^{*} \arcsin \eta / a \text {. }
$$

At the tidal front, $x=x_{f}, h=0$, and, from (5), $Z=\eta$. Eliminating $\eta$ and $x_{f}$ in (14) and solving for $Z$ then gives 


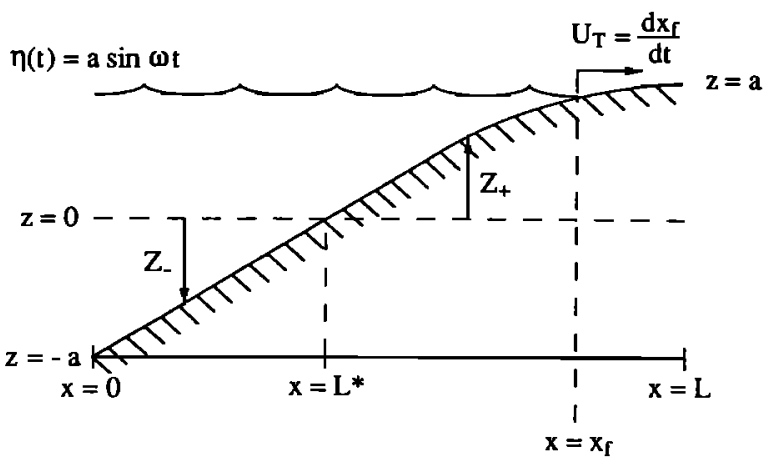

Figure 5. Schematic side view of an equilibrium flat along a straight shoreline which is dominated by tidal currents. $Z_{-}$is the elevation of the lower profile, $Z_{+}$is the elevation of the upper profile, $L^{*}$ is the $x$ location of $Z=0$.

$$
Z_{+}(x)=a \sin \left(x / L^{*}-1\right) \text { for } x>L^{*}
$$

Since $\mathrm{Z}_{+}=\mathrm{a}$ at $\mathrm{x}=\mathrm{L}$, from (15) it is clear that for an equilibrium flat along a straight shoreline,

$$
L^{*} / L=(\pi / 2+1)^{-1} .
$$

The equilibrium profile given by (11) and (15) is illustrated in Figure $6 a$ by the curve labeled "straight shoreline". Figure 6a indicates that the equilibrium profile for a current-dominated flat along a straight shoreline is convex relative to the linear profile. In Figure $6 \mathrm{~b}$, the curve labeled "straight shoreline" displays the corresponding hypsometry, which is identical to the profile for the straight shoreline case. Thus the results of this section indicate that tidal currents favor a convex hypsometry at equilibrium (at least along a straight shoreline), consistent with the general observational trends presented earlier.

Finally, (16) can be used to constrain the equilibrium length of a tidal flat in the absence of wind waves if there exists some characteristic magnitude of $U_{T}$ at equilibrium. If $U_{T}=u_{e q}$, where $u_{e q}$ is some (externally fixed) velocity at equilibrium, then (16), along with the relation $U_{T}=L^{*} \omega$, yields

$$
\mathrm{L}=(\pi / 2+1) \mathrm{u}_{\mathrm{eq}} / \omega \text {. }
$$

If $u_{e q}=30 \mathrm{~cm} \mathrm{~s}^{-1}$ during an $M_{2}$ tide, then (17) gives $L=5.5 \mathrm{~km}$, where $L$ is the length of the flat in the direction of maximum tidal velocity. Thus it is only necessary for the component of the flat perpendicular to the bathymetric contours to be of length $L \cos \theta$, where $\theta$ is the angle between the velocity and the shoreline. Also, intertidal flats may not extend all the way to high water, but rather may abut 
salt marsh. If a flat along a straight shoreline extends from low water to mean water, for example, it need only have a length $L^{*}=u_{e q} / \omega$ parallel to the velocity direction. If $\mathrm{u}_{\mathrm{eq}}=30 \mathrm{~cm} \mathrm{~s}^{-1}, \theta=45^{\circ}$, and the flat in question lies below mean water, then the shore-normal component of the flat need only extend $1.5 \mathrm{~km}$.

If a tidal flat abuts salt marsh, then its equilibrium hypsometry will be altered along with its horizontal extent. Intertidal marsh is generally concentrated in the upper portion of the intertidal zone with its lower extent limited by the frequency of submergence (Redfield, 1972; Frey and Basan, 1985). Since the convex portion of the "straight shoreline" hypsometry in Figure 6 is also limited to the upper part of the tidal range, overall tidal flat convexity will be reduced by the presence of salt marsh.
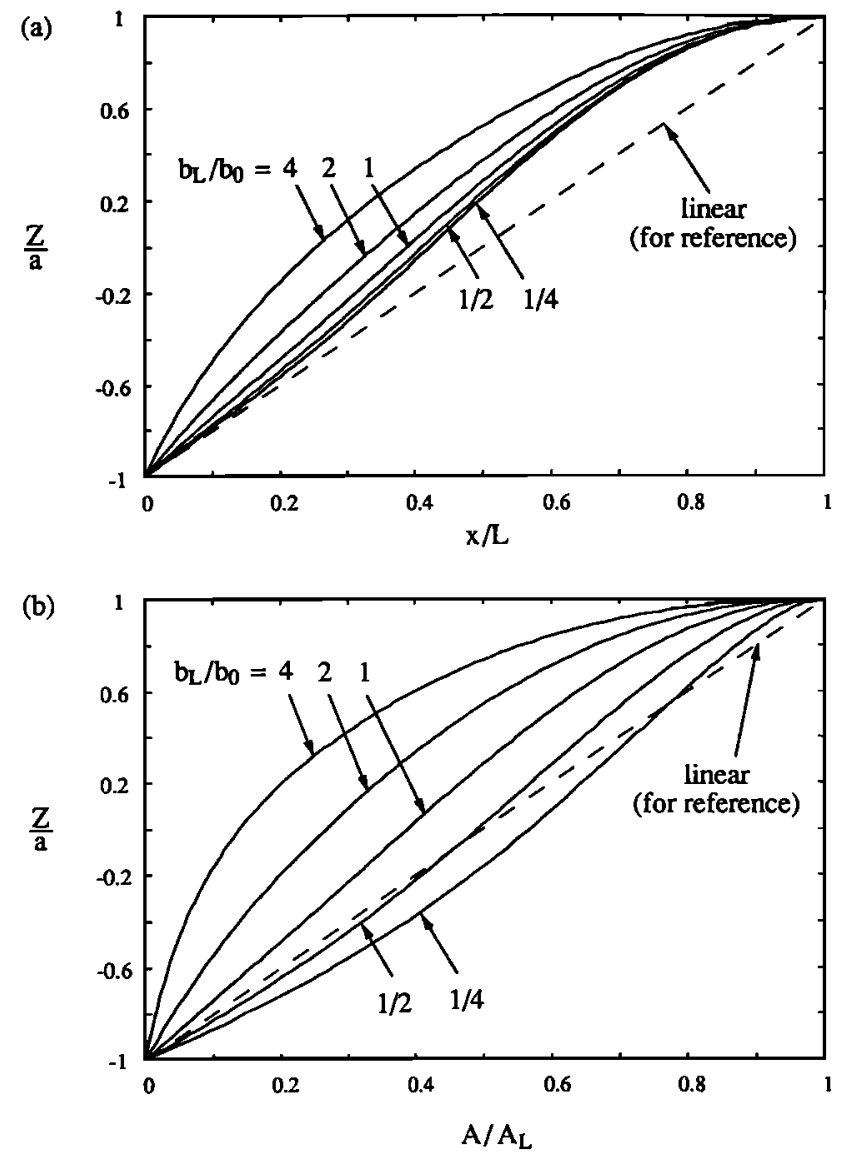

Figure 6. Equilibrium flats dominated by tidal currents. (a) profiles and (b) hypsometries. $b_{L} / b_{0}$ is the flat width (parallel to the shoreline) at $x=L$ divided by its width at $x=0$. $b_{L} / b_{0}>1$ for an embayed shoreline, $b_{L} / b_{0}=1$ for a straight shoreline, and $b_{L} / b_{0}<1$ for $a$ lobate shoreline. 


\section{Curved Shoreline, Equilibrium Flat}

The effect of shoreline curvature on equilibrium profiles and hypsometries dominated by $\tau_{\mathrm{T}}$ is now considered. Figure 7 provides plan views of "lobate" and "embayed" shorelines with tidal flats extending from $x=0$ to $x=L$. A lobate shoreline has a shore-parallel width at $x=L$ which is less than its width at $x=0$, giving $b_{L} / b_{0}<1$. An embayed shoreline has $b_{L} / b_{0}>1$, and a straight shoreline has $b_{L} / b_{0}=1$.

For a curved shoreline which is radially symmetric, continuity is easily evaluated in polar coordinates:

$$
\frac{d \eta}{d t}+\frac{1}{r} \frac{d}{d r}\left\{r h(r, t) u_{T}(r, t)\right\}=0
$$

In this section tidal flow is assumed everywhere to be perpendicular to the bathymetry. Equation (18) integrates to

$$
u_{T}(r, t)=\frac{r_{f}{ }^{2}-r^{2}}{2 r h(r, t)} \frac{d \eta}{d t},
$$

where $r_{f}$ is the position of the tidal front. Keeping in mind that $b$ is proportional to $r$ (see Figure 7), (19) may be re-expressed as

$$
\mathbf{u}_{\mathrm{T}}(\mathrm{r}, \mathrm{t})=\frac{1}{2}\left(\mathrm{~b}\left(\mathrm{r}_{\mathrm{f}}\right) / \mathrm{b}(\mathrm{r})+1\right) \frac{\mathrm{r}_{\mathrm{f}}-\mathrm{r}}{\mathrm{h}(\mathrm{r}, \mathrm{t})} \frac{\mathrm{d} \eta}{\mathrm{dt}} .
$$

Transforming back to the $x$-coordinate, $r=r_{0} \pm x, r_{f}=r_{0} \pm x_{f}$, and $u_{T}(r, t)= \pm u_{T}(x, t)$, where $r_{0}=r(x=0)$, and the \pm corresponds to a shoreline that is embayed $(+)$ or lobate (-). Then (20) becomes

$$
u_{T}(x, t)=B\left(x_{f}, x\right) \frac{x_{f}-x}{h(x, t)} \frac{d \eta}{d t},
$$

where

$$
B\left(x_{f}, x\right)=\frac{1}{2}\left(b\left(x_{f}\right) / b(x)+1\right),
$$

and

$$
\mathrm{b}(\mathrm{x}) / \mathrm{b}_{0}=1+\left(\mathrm{b}_{\mathrm{L}} / \mathrm{b}_{0}-1\right) \mathrm{x} / \mathrm{L} .
$$

Equations (21) - (23) are valid for any radially symmetric flat, regardless of the precise form of the profile.

If shoreline curvature is negligible (i.e., $\left.b_{L} / b_{0}=1\right)$, then $b\left(x_{f}\right)=b(x), B=1$, and (20) is identical to (4). If the shoreline is lobate $\left(b_{L} / b_{0}<1\right)$, then $b(x) \geq b\left(x_{f}\right)>0$, and $B$ is bounded by $1 / 2<B \leq 1$. If the shoreline is embayed $\left(b_{L} / b_{0}>1\right)$, 
LOBATE shoreline:

EMBAYED shoreline:
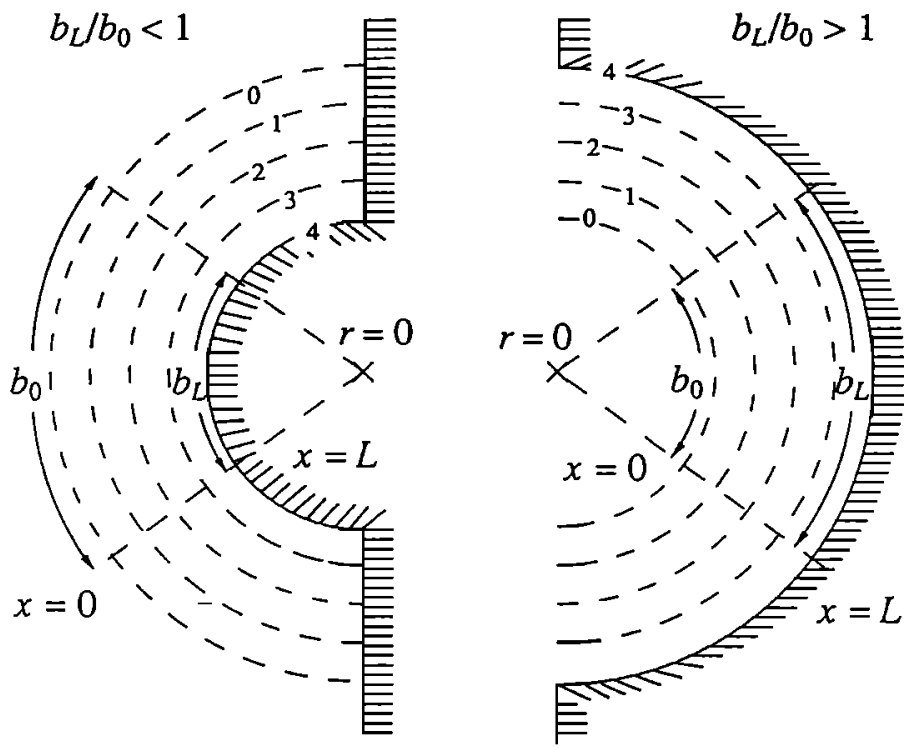

Figure 7. Schematic plan view of a lobate and an embayed shoreline. The contours $0-4$ are arbitrary heights between low and high water.

then $0<b(x) \leq b\left(x_{f}\right)$, and $B$ is bounded by $1 \leq B<\infty$. Thus $B$ is less sensitive to lobate shorelines and more sensitive to embayed shorelines.

The derivation of equilibrium tidal flat profiles along curved shorelines in the absence of wind waves closely follows that used for straight shorelines. By analogy to previous section, different relations are assumed to govern the equilibrium profile for $\mathrm{x} \leq \mathrm{L}^{*}$ and $\mathrm{x}>\mathrm{L}^{*}$. Also, as before it is assumed that $\mathrm{U}_{\mathrm{T}}=\mathrm{L}^{*} \omega$ occurs simultaneously across all of $x \leq L^{*}$ when $x_{f}=L^{*}$. However, $\eta$ is not assumed to be equal to zero when $x_{f}=L^{*}$. Rather, $\eta=z^{*}$ when $x_{f}=L^{*}$, where $z^{*}$ may be less than or greater than zero, depending on the nature of the shoreline curvature. For $x>L^{*}$, it is again assumed that $U_{T}$ occurs at the tidal front, i.e., $\mathbf{d x}_{\mathbf{f}} / \mathrm{dt}=\mathrm{L}^{*} \omega$.

In order to determine $z^{*},(21)$ is evaluated at $x=0$ when $x_{f}=L^{*}$. Under these circumstances, (21) becomes

$$
\mathrm{U}_{T}=\mathrm{L}^{*} \omega=\mathrm{B}\left(\mathrm{L}^{*}, 0\right) \frac{\mathrm{L}^{*}}{\mathrm{Z}^{*}+\mathrm{a}} \frac{\mathrm{d} \eta\left(\mathrm{Z}^{*}\right)}{\mathrm{dt}} .
$$

Using the expression $d \eta / d t=a \omega\left(1-\eta^{2} / a^{2}\right)^{1 / 2}$, and solving for $z^{* / a}$ then gives:

$$
z^{*} / \mathrm{a}=\frac{\mathrm{B}\left(\mathrm{L}^{*}, 0\right)^{2}-1}{\mathrm{~B}\left(\mathrm{~L}^{*}, 0\right)^{2}+1}
$$


If the shoreline is lobate, then $\mathrm{B}<1$, and $\mathrm{z}^{*}$ is negative. If the shoreline is embayed, then $B>1$, and $z^{*}$ is positive. Finally, if the shoreline is straight, $B=1$, and $\mathrm{z}^{*}=0$.

The form of the tidal profile for $x \leq L^{*}$ is found by solving for $Z_{-}(x)$ in (21) with $h=\eta-Z_{-}, u_{T}=L^{*} \omega, x_{f}=L^{*}$, and $\eta=z^{*}$. Then (21) becomes

$$
Z_{-}(x) / a=z^{*} / a-B\left(L^{*}, x\right)\left(1-x / L^{*}\right)\left(1-\frac{z^{*^{2}}}{a^{2}}\right)^{1 / 2} \text { for } x \leq L^{*} \text {. }
$$

If the shoreline is straight, then $B=1, z^{*}=0$, and (26) is identical to (11).

For $x>L^{*}$, it is assumed that $U_{T}$ occurs at the tidal front, i.e., $U_{T}=L^{*} \omega=d x_{f} / d t$. Proceeding as in previous section, integration of $d x_{f} / d \eta=d x_{f} / d t d t / d \eta$, followed by setting $x_{f}=x$ and $\eta=Z_{+}$yields

$$
\mathrm{Z}_{+}(\mathrm{x}) / \mathrm{a}=\sin \left\{\left(\mathrm{x} / \mathrm{L}^{*}-1\right)+\arcsin \mathrm{z}^{*} / \mathrm{a}\right\} \text { for } \mathrm{x}>\mathrm{L}^{*} \text {. }
$$

If $\mathrm{z}^{*}=0$, (27) becomes equivalent to (15). Since $\mathrm{Z}_{+}=\mathrm{a}$ at $\mathrm{x}=\mathrm{L},(27)$ can be used to derive $\mathrm{L}^{*}$ relative to $\mathrm{L}$ :

$$
L^{*} / \mathrm{L}=\left(\pi / 2+1-\arcsin z^{* / a}\right)^{-1} .
$$

If $\mathbf{z}^{*}=0,(28)$ reverts to (16).

Profiles given by (26) - (27) indicate that an embayed shoreline $\left(b_{L} / b_{0}>1\right)$ significantly enhances the convexity of the equilibrium tidal profile, whereas a lobate shoreline $\left(b_{L} / b_{0}<1\right)$ only slightly decreases the convexity of the profile (Figure 6a). This behavior is consistent with the function B, given by (22), which is also more sensitive to embayed shorelines.

Finally the profiles of Figure $6 \mathrm{a}$ are re-expressed as hypsometries, which are not equivalent to $Z(x)$ if the shoreline is curved. Hypsometries are plots of elevation versus cumulative basin area, $A$, where $A(x)=\int b\left(x^{\prime}\right) d x^{\prime}$. Integration of (23) yields:

$$
\frac{A(x)}{A(L)}=\frac{2 x / L+\left(b_{L} / b_{0}-1\right)(x / L)^{2}}{1+b_{L} / b_{0}}
$$

If the shoreline is straight, then $b_{L} / b_{0}=1$, and (29) reduces to $A(x) / A(L)=x / L$. Equilibrium hypsometries for embayed shorelines are much more convex than the corresponding profiles (Figure 6b). Likewise, hypsometries for lobate shorelines are much less convex than the corresponding profiles - so much so that the equilibrium hypsometry for a current-dominated flat with $b_{L} / b_{0}=1 / 4$ is primarily concave. The enhanced variation of hypsometries relative to profiles stems from the nonlinear hypsometric function given by (29). 


\section{Wind Waves}

The derivation for wave-dominated conditions parallels that described by Zimmerman (1973), who also examined the distribution of maximum bottom shear stress due to shoaling waves. The approach here differs in that Zimmerman did not apply the shallow water approximation nor did he consider waves shoaling across a linear profile.

The governing equation applied to wind waves in the absence of tidal currents is conservation of energy for monochromatic, remotely forced, forward propagating, shallow water surface waves:

$$
\frac{d}{d x}\left\{E(x) C_{g}(x)\right\}=-D(x)
$$

where $E$ is wave energy, $C_{g}=(g h)^{1 / 2}$ is the wave group velocity, $g$ is the acceleration of gravity, and $\mathrm{D}$ is dissipation by bottom friction. In this section wind waves propagate perpendicular to the shoreline with no refraction across the flat. In evaluating (30) neither breaking waves nor wave energy reflected from the shoreline are considered. Thus this approach is inappropriate for energetic, steep beaches. However for gently sloping, highly dissipative tidal flats, the approach should be adequate for gaining useful physical insight. It is also assumed that the largest waves are most likely to occur around the time of high water. This is a reasonable assumption in enclosed intertidal basins because fetch will be smaller near low tide. It is also a reasonable assumption for open coasts if the intertidal slope continues some distance offshore. Then offshore dissipation will be greater at lower tide levels, reducing the height of waves impinging on the flats.

Wave energy in (30) is given by

$$
E(x)=1 / 8 \rho g H(x)^{2},
$$

where $\rho$ is the fluid density, and $\mathrm{H}$ is the wave height. Frictional dissipation in (30) is given by

$$
D(x)=\frac{1}{T_{W}} \int_{0}^{T_{W}}\left\{\rho c_{d} u_{W} l_{u_{W}} \mid\right\} u_{W} d t
$$

where $T_{W}$ is the wave period, $u_{W}$ is instantaneous wave velocity, and the quantity in brackets is instantaneous wave-generated bottom shear stress. If

$$
u_{W}(x, t)=U_{W}(x) \sin \left(2 \pi t / T_{W}\right),
$$

then substitution of (33) into (32) followed by integration gives

$$
D(x)=\frac{4}{3 \pi} \rho c_{d} U_{W}{ }^{3}
$$


The above relations for $E(x)$ and $D(x)$, along with the relation $C_{g}=(g h)^{1 / 2}$, are substituted into (30), and (2) is used to eliminate $H(x)$. The result is a non-linear ordinary differential equation for $U_{W}$ :

$$
\frac{1}{U_{W}^{2}} \frac{d}{d x} U_{W}+\frac{3}{4 h U_{W}} \frac{d h}{d x}=-\frac{4 c_{d}}{3 \pi g^{1 / 2} h^{3 / 2}} .
$$

Equation (35) can be rewritten as a linear O.D.E for $\mathrm{U}_{\mathrm{W}^{-1}}$ :

$$
\frac{d}{d x} U_{W}^{-1}-\frac{3}{4 h} \frac{d h}{d x} U_{W}^{-1}=\frac{4 c_{d}}{3 \pi g^{1 / 2} h^{3 / 2}}
$$

The boundary condition on (36) is $\mathrm{UW}_{\mathrm{W}}^{-1}=\mathrm{UW}_{0}{ }^{-1}$ at $\mathrm{x}=0$, which may determined from $H(x=0)$ via (2). Assuming $h(x)$ is known, then (36) can be solved completely for $U_{W}$.

\section{Straight Shoreline, Linear Profile}

Figure 8 displays a linearly sloping tidal flat of length $L$, where $L$ is the shore-normal distance from the low to high water line. The depth of the tidal flat profile is:

$$
h(x)=(L-x) h_{0} / L,
$$

where $h_{0}$ is the high-water depth at $x=0$ and also is equal to the tidal range.

Substituting (37) into (36) yields

$$
(L-x) \frac{d}{d x} U_{W}^{-1}+\frac{3}{4} U_{W}^{-1}=C_{1}(L-x)^{-1 / 2}
$$

with

$$
C_{1}=\frac{4 c_{d} L^{3 / 2}}{3 \pi g^{1 / 2} h_{0}^{3 / 2}}
$$

From the right hand side of (38), the particular solution for $\mathrm{U}_{\mathrm{W}^{-1}}$ will have the form

$$
\left\{\mathrm{U}_{\mathrm{W}^{-1}}\right\}_{\text {part }}=\mathrm{C}_{2}(\mathrm{~L}-\mathrm{x})^{-1 / 2} \text {. }
$$

Substituting (40) into (38) yields $C_{2}=4 / 5 C_{1}$. The homogeneous portion of (38) integrates to:

$$
\left\{\mathrm{U}_{\mathrm{W}^{-1}}\right\}_{\text {homo }}=\mathrm{C}_{3}(\mathrm{~L}-\mathrm{x})^{3 / 4}
$$

Finally, the boundary condition at $x=0$ gives $C_{3}=U_{W_{0}}^{-1} L^{-3 / 4}-C_{2} L^{-5 / 4}$. 


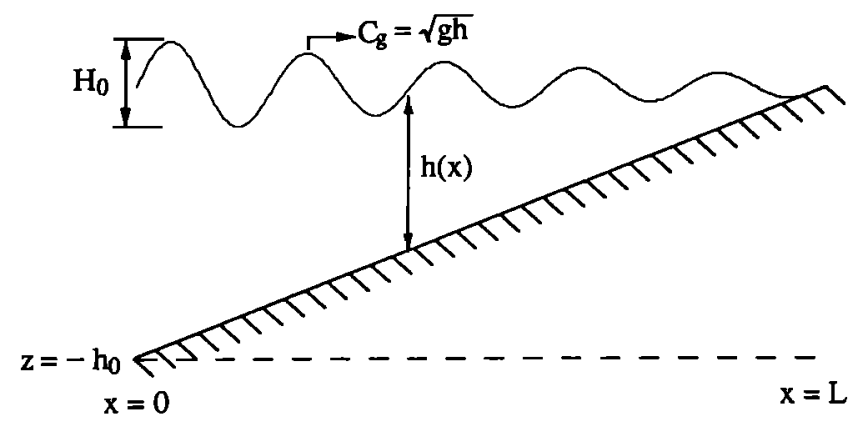

Figure 8. Schematic side view of a linearly sloping flat along a straight shoreline which is dominated by wind waves. $\mathrm{H}_{0}$ is offshore wave height, $\mathrm{C}_{\mathrm{g}}$ is wave velocity, $\mathrm{h}$ is local depth at high water, $h_{0}$ is high water depth at $x=0$ and also equals the tidal range.

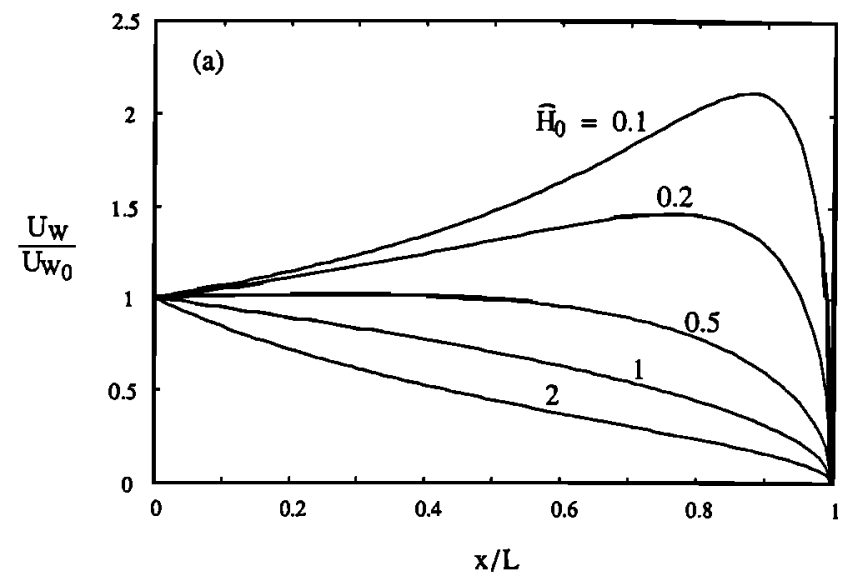

Figure 9. Maximum wave orbital velocity as a function of non-dimensional offshore wave height, $\mathrm{A}_{0}$, and of distance across a flat which slopes linearly away from a straight shoreline.

Combining the above equations yields:

$$
\mathrm{U}_{\mathrm{W}}(\mathrm{x}) / \mathrm{UW}_{0}=\left\{\hat{\mathrm{H}}_{0}(1-\mathrm{x} / \mathrm{L})^{-1 / 2}+\left(1-\hat{\mathbf{H}}_{0}\right)(1-\mathrm{x} / \mathrm{L})^{3 / 4}\right\}^{-1},
$$

where the non-dimensional forcing wave height, $\hat{\mathrm{H}}_{0}$ is given by

$$
\overline{\mathrm{H}}_{0}=\frac{16}{15 \pi} c_{d} \frac{\mathrm{L}}{\mathrm{h}_{0}} \frac{\mathrm{U}_{\mathrm{W}_{0}}}{\left(\mathrm{gh}_{0}\right)^{1 / 2}}=\frac{8}{15 \pi} \mathrm{c}_{\mathrm{d}} \frac{\mathrm{LH}_{0}}{\mathrm{~h}_{0}{ }^{2}} .
$$

No value of $\hat{H}_{0}$ for a linearly sloping tidal flat results in a uniform distribution of $U_{W}$ across the flat (Figure 9). Thus, according to the morphodynamic model applied here, a linearly sloping flat dominated by wind waves cannot be at equilibrium. 


\section{Straight Shoreline, Equilibrium Profile}

A tidal flat profile is now derived which results in a uniform distribution of $U_{W}$ across the entire flat. A similar solution was found previously by Bruun (1954) who assumed energy dissipation to be uniform across an equilibrium shoreface. However Bruun ignored the effect of shoreline curvature (see below).

Deriving an equilibrium profile with $\mathrm{UW}_{\mathrm{W}}=\mathrm{UW}_{0}$ everywhere is simpler than solving for $U_{W}(x)$. If $U_{W}$ is constant, the first term in (35) is zero, and (35) may be rewritten as

$$
h^{1 / 2} d h=-\frac{16}{9 \pi} c_{d} U_{W_{0}} g^{-1 / 2}(L-x)
$$

Equation (44) integrates to

$$
h(x) / h_{0}=(1-x / L)^{2 / 3},
$$

where

$$
h_{0}=\left(\frac{8}{3 \pi} c_{d} U_{W_{0}} g^{-1 / 2} L\right)^{2 / 3}
$$

Equation (46) can be crudely checked by comparison to the Korean values. If (46) is solved for $U W_{0}$, then $c_{d}=0.01, L=5 \mathrm{~km}$, and $h_{0}=6 \mathrm{~m}$ give $U W_{0}=1.1 \mathrm{~ms}^{-1}$, which is a value that is certainly capable of mobilizing sediment. Using (2), this velocity is equivalent to a forcing wave height of $\mathrm{H}_{0}=1.7 \mathrm{~m}$, which seems like a reasonable value for typical wave dominated conditions.

The equilibrium profile given by (45) is illustrated in Figure 10a by the curve labeled $b_{L} / b_{0}=1$. Figure $10 a$ indicates that the equilibrium profile for a wavedominated flat along a straight shoreline is concave relative to the linear profile. In Figure $10 \mathrm{~b}$, the curve labeled $b_{L} / b_{0}=1$ displays the corresponding hypsometry, which is identical to the profile for the straight shoreline case. Thus (45) indicates wind-waves favor a concave hypsometry at equilibrium (at least along a straight shoreline), which is consistent with the observations summarized in the Introduction.

Finally, (46) can be used to derive the equilibrium length for a flat under wavedominated conditions. If $\mathrm{H}_{0}, \mathrm{~h}_{0}$ and $\mathrm{c}_{\mathrm{d}}$ are considered to be characteristic values, independent of the extent of the tidal flat, then (46) and (2) can be combined and solved for L:

$$
L=\frac{3 \pi}{4 c_{d}} \frac{h_{0}^{2}}{H_{0}}
$$

Equation (47) seems qualitatively sensible in that it indicates that equilibrium tidal flat width decreases with increasing wave height, $\mathrm{H}_{0}$, and increases dramatically with increasing tidal range, $h_{0}$. Equation (47) suggests that the position of the low 

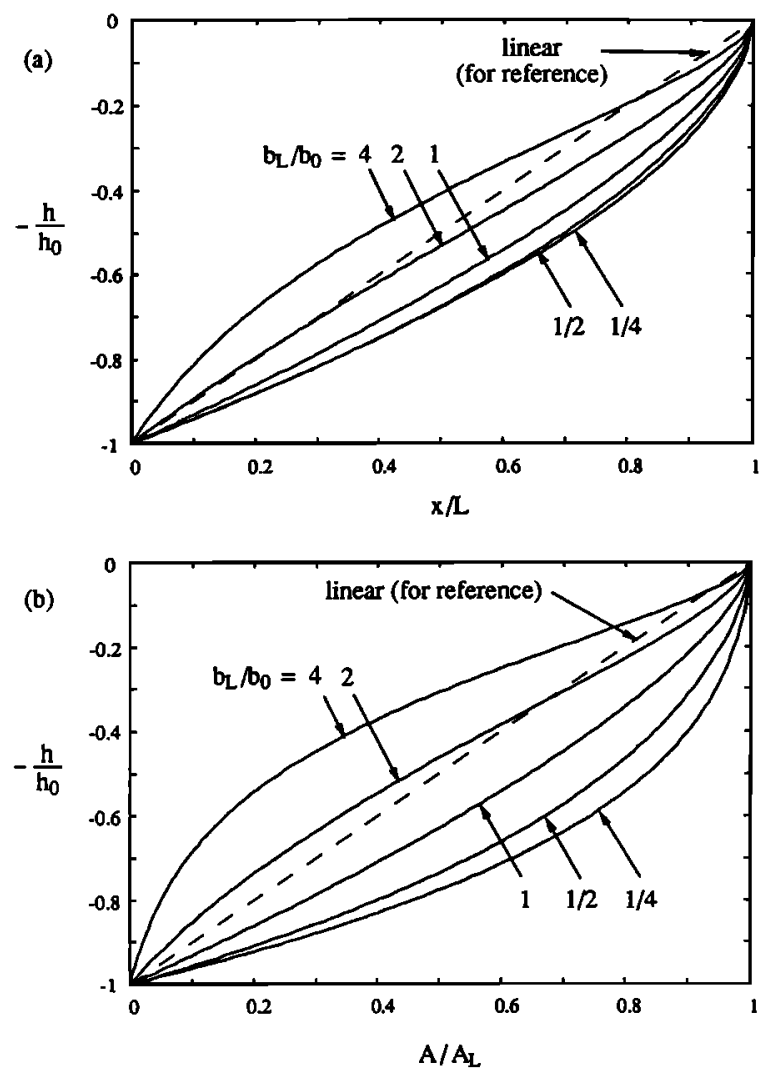

Figure 10. Equilibrium flats dominated by wind waves. (a) profiles and (b) hypsometries. $b_{L} / b_{0}>1$ for an embayed shoreline, $b_{L} / b_{0}=1$ for a straight shoreline, and $b_{L} / b_{0}<1$ for a lobate shoreline.

tide line should oscillate with seasonal variations in forcing wave height. This predicted oscillation is qualitatively consistent with the observations of Wells and Park (1992).

Equation (47) may also help explain the associations of small tidal ranges with concave hypsometry and of large tidal ranges with convex hypsometry illustrated in Figure 2a (Dieckmann $e t$ al., 1987). If wave height is moderate and tidal range is small, (47) indicates that $L$ will also be small. Before, $U_{T}$ was found to be directly proportional to $L$. Thus if $L$ is small, $U_{T}$ will be small also. Under these conditions, $U_{W}$ and $\tau_{W}$ will dominate $U_{T}$ and $\tau_{T}$, and the equilibrium profile will be concave. If tidal range is large and waves are moderate, then (47) indicates $L$ will be much larger (since $L$ is geometrically dependent on $h_{0}$ ). Since $U_{T}$ is proportional to $L, U_{T}$ will also be much larger. $U_{W}$ and $\tau_{\mathrm{W}}$ may no longer dominate $U_{T}$ and $\tau_{T}$, at least under fair weather conditions, and the equilibrium profile may be more convex. 


\section{Curved Shoreline, Equilibrium Profile}

The effect of shoreline curvature on equilibrium profiles and hypsometries dominated by $\tau_{\mathrm{W}}$ is now considered. For a curved shoreline which is radially symmetric (see Figure 7), conservation of energy is easily evaluated in polar coordinates:

$$
\frac{1}{r} \frac{d}{d r}\left\{r E(r) C_{g}(r)\right\}=-D(r),
$$

It is assumed that refraction has already caused the wind waves to propagate nearly perpendicular to the bathymetric contours by the time the waves reach the edge of the flat at $\mathrm{r}_{0}=\mathrm{r}(\mathrm{x}=0)$.

Evaluation of (48) is straightforward if $U_{W}=U_{0}$ across the entire profile. Using (2), (31), (34) and the relation $C_{g}=(g h)^{1 / 2}$, (48) integrates to

$$
\mathrm{rh}^{3 / 2}=\frac{4}{3 \pi} \mathrm{c}_{\mathrm{d}} \mathrm{U}_{\mathrm{W}_{0}} \mathrm{~g}^{-1 / 2}\left|\mathrm{r}_{\mathrm{L}}{ }^{2}-\mathrm{r}^{2}\right|
$$

where $r_{L}=r(x=L)$. Since $b$ is proportional to $r$ (see Figure 7), (49) may be reexpressed as

$$
h(r)^{3 / 2}=\frac{1}{2}\left(b\left(r_{L}\right) / b(r)+1\right) \frac{8 c_{d} U_{W_{0}}}{3 \pi g^{1 / 2}}\left|r-r_{L}\right| .
$$

Transforming back to the $\mathrm{x}$-coordinate, $(50)$ becomes

where

$$
h(x) / h_{0}=\{B(L, x) / B(L, 0)\}^{2 / 3}(1-x / L)^{2 / 3},
$$

$$
h_{0}=\left(B(L, 0) \frac{8}{3 \pi} c_{d} U_{W_{0}} g^{-1 / 2} L\right)^{2 / 3},
$$

and

$$
B(L, x)=\frac{1}{2}\left(b_{L} / b(x)+1\right) .
$$

$B(L, x)$ is analogous to $B\left(x_{f}, x\right)$ in equation (22), and $b(x)$ above is identical to (23). If shoreline curvature is negligible (i.e., $b_{L} / b_{0}=1$ ), then $b_{L}=b(x), B=1$, and (51) (52) become identical to (45) - (46).

Profiles given by $(51)$ indicate that a lobate shoreline $\left(b_{L} / b_{0}<1\right)$ only slightly increases the concavity of the profile, whereas an embayed shoreline $\left(b_{L} / b_{0}>1\right)$ greatly decreases the concavity of the profile - so much so that the equilibrium profile for a flat with $b_{L} / b_{0}=4$ is primarily convex (Figure 10a). The greater sensitivity of the profile to embayed shorelines is similar to that under tidal currents 
(see Figure 6a) which follows from a dependence of the equilibrium profile on the function $B$, which is also more sensitive to embayed shorelines.

Finally, the profiles of Figure 10a can be re-expressed as hypsometries (Figure 10b). Equilibrium hypsometries for lobate shorelines $\left(b_{L} / b_{0}<1\right)$ are significantly more concave than the corresponding profiles, and hypsometries for embayed shorelines $\left(b_{L} / b_{0}>1\right)$ are significantly less concave. In fact, the hypsometries for $b_{L} / b_{0} \geq 2$ are primarily convex. The range of hypsometries in Figure $10 \mathrm{~b}$ are qualitatively similar to the hypsometries observed by Kirby (1992) within the Severn Estuary (see Figure 2). Kirby included a location map, reproduced in Figure 11, which outlines the shoreline along the Severn. The shoreline at Cardiff Bay (which has a convex hypsometry) is strongly embayed, whereas the shoreline at Clevedon (which has a concave hypsometry) is straight to slightly lobate. Thus it is possible that shoreline shape has contributed to the hypsometric trends reported by Kirby.
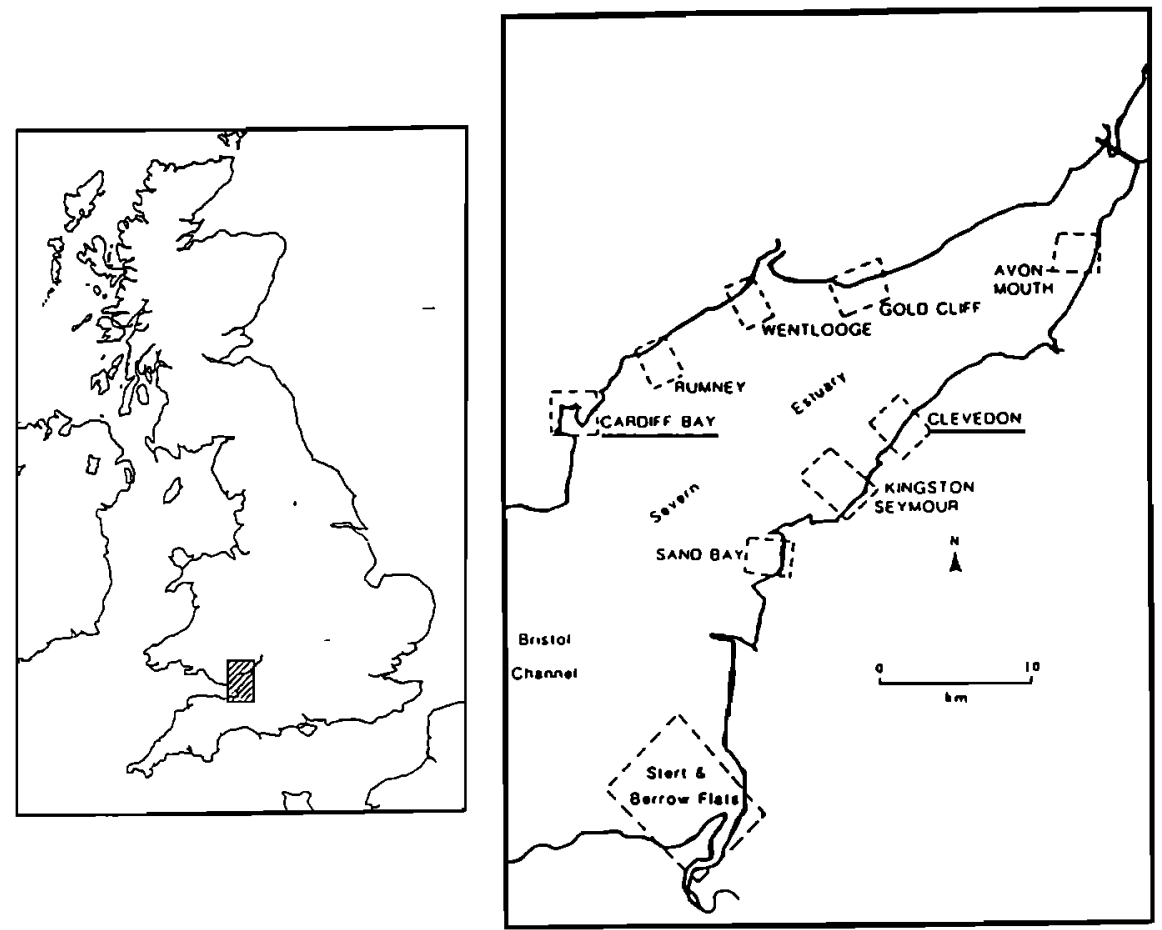

Figure 11. Location map showing flats along the Severn for which Kirby performed hypsometric analysis, modified from Kirby (1992). Cardiff Bay and Clevedon (underlined) have strongly convex and strongly concave hypsometries, respectively (see Figure 2). 


\section{Conclusions}

Recent observations of tidal flat hypsometry have correlated convexity with large tide ranges, long-term accretion and/or low wave activity. Concavity, in turn, has been correlated with small tide ranges, long-term erosion and/or high wave activity. This study demonstrates that much of this empirically observed variation in tidal flat hypsometry is consistent with a simple morphodynamic model which assumes tidal flats to be at equilibrium if maximum shear stress is uniform in space. Assuming a constant drag coefficient, this condition is equivalent to a uniform distribution of maximum velocity.

In the absence of wind waves, maximum shear stress is a function of maximum tidal velocity, $U_{T}$. Assuming the intertidal excursion to be much shorter than the tidal wave length, continuity may be solved kinematically to determine $U_{T}$ as a function of distance across the flat. For a flat which slopes linearly away from a straight shoreline, results show that $U_{T}$ is constant across the seaward half of the flat. Therefore the lower portion of a linearly sloping flat is potentially at morphologic equilibrium. Across the landward half, however, a dramatic decrease in $U_{T}$ is predicted, indicating disequilibrium.

For a straight waveless shoreline, the equilibrium profile has a linear slope over the seaward portion of the flat, and $U_{T}$ occurs at mid-tide. Across the landward portion of the flat, $U_{T}$ is assumed to occur at the tidal front. The equilibrium value for $U_{T}$ is then proportional to the length of the tidal flat but is independent of tidal range. The resulting equilibrium profile is convex overall and demonstrates that tidal currents favor a convex hypsometry along a straight shoreline.

For a curved waveless shoreline, the equilibrium flat is derived in a similar manner. Results indicate that an embayed shoreline significantly enhances the convexity of the equilibrium profile, whereas a lobate shoreline only slightly decreases the convexity. The nonlinear transformation from profiles to hypsometries, however, causes the hypsometry of embayed and lobate shorelines to be much more or much less convex than the corresponding profiles - so much so that the effect of shoreline curvature on equilibrium hypsometry is potentially as strong as the effect of domination by tidal currents.

In the presence of wind waves, shear stress is often dominated by the maximum wave orbital velocity, $U_{W}$. Assuming dissipative shallow water waves impinging at high water, conservation of energy is utilized to determine $U_{W}$ as a function of distance across the flat. For a flat sloping linearly away from a straight shoreline, the solution may be expressed in terms of a single dimensionless forcing wave height, $\overline{\mathrm{H}}_{0}$. No value of $\overline{\mathrm{H}}_{0}$ results in a uniform distribution of $U_{W}$, thus no part of a linearly sloping, wave-dominated flat is at equilibrium.

The equilibrium flat along a straight, wave-dominated shoreline is derived by setting $U_{W}$ constant in the previously derived governing equation for $U_{W}{ }^{-1}$. The resulting equilibrium profile has depth increasing as $x^{2 / 3}$, indicating wind waves favor a 
concave hypsometry. Under domination by waves, the equilibrium profile length, L, is proportional to $h_{0}^{2} / H_{0}$, where $h_{0}$ is the tidal range and $H_{0}$ is the forcing wave height. This expression suggests $L$ should increase dramatically with tidal range. Since $U_{T} \sim \mathrm{L}$, the relative importance of tidal currents should also increase strongly with tidal range, favoring a transition from concave to convex hypsometry with increasing tidal range.

An equilibrium flat along a curved, wave-dominated shoreline is derived in a similar manner. Like the no-wave case, results indicate that an embayed shoreline significantly decreases the concavity of the profile - potentially to the point of convexity - whereas a lobate shoreline only slightly increases concavity. Again, the nonlinear transformation from profiles to hypsometries causes the hypsometries to be much more or much less concave than the profiles.

Acknowledgements. Special thanks are extended to J. Boon, R. Kirby, D. Lynch, O. Madsen, and J. Trowbridge who provided helpful comments on the manuscript. This work was supported by the National Science Foundation, under grant number OCE 91-02429. WHOI contribution No. 8294.

\section{References}

Alexander, C. R., C. A. Nittrouer, D. J. Demaster, Y.-A. Park and S.-C. Park, Macrotidal mudflats of the southwestern Korean coast: a model for interpretation of intertidal deposits. $J$. Sediment. Petrol., 61, 805-824, 1991.

Boon, J. D., Tidal discharge asymmetry in a salt marsh drainage system. Limnol. Oceanogr., 20, 71-80, 1975.

Boon, J. D., and R. J. Byrne, On basin hypsometry and the morphodynamic response of coastal inlet systems. Mar. Geol., 40, 27-48, 1981.

Bruun, P., Coast erosion and the development of beach profiles. U.S. Army Corps of Engineers, Beach Erosion Board, Tech. Memo. 44, 79 pp, 1954.

Davies, J. L., Geographical Variation in Coastal Development. New York: Hafner, 204 pp, 1973.

Dieckmann, R., M. Osterthun and H. W. Partenscky, Influence of water-level elevation and tidal range on the sedimentation in a German tidal flat area. Progress in Oceanogr., 18, 151 166, 1987.

Dyer, K. R., Coastal and estuarine sediment dynamics. New York: Wiley, 342 pp, 1986.

Frey, R. W., and P. B. Basan, Coastal salt marshes, in Coastal Sedimentary Environments edited by R. A. Davis, 225-302, Springer-Verlag, New York, 1985.

Friedrichs, C. T., D. R. Lynch and D. G. Aubrey, Velocity asymmetries in frictionallydominated tidal embayments: longitudinal and lateral variability, in Dynamics and Exchanges in Estuaries and the Coastal Zone. Coastal and Estuarine Studies, edited by D. Prandle, American Geophysical Union, Washington, D.C., 40, 277-312, 1992.

Grant, W. D., and O. S. Madsen, Combined wave and current interaction with a rough bottom. J. Geophys. Res., 84, 1797-1808, 1979.

Kirby, R., Effects of sea-level on muddy coastal margins, in Dynamics and Exchanges in Estuaries and the Coastal Zone. Coastal and Estuarine Studies, edited by D. Prandle, American Geophysical Union, Washington, D.C., 40, 313-334, 1992. 
Klein, G. D., Intertidal flats and intertidal sand bodies, in Coastal Sedimentary Environments, edited by R. A. Davis, Springer-Verlag, New York, 187-218, 1985.

Pethick, J. S., Velocity surges and asymmetry in tidal channels. Estuarine and Coastal Marine Science, 11, 331-345, 1980.

Redfield, A. C., Development of a New England salt marsh. Ecological Monographs, 42, 201 $237,1972$.

Strahler, A. N., Hypsometric (area-altitude) analysis of erosional topography. Geological Soc. America Bull., 63, 1117-1142, 1952.

Wells, J. T., C. E. Adams, Y.-A. Park and E. W. Frankenberg, Morphology, sedimentology and tidal channel processes on a high-tide-range mudflat, west coast of Korea. Mar. Geol., 95, 111-130, 1990.

Wells, J. T., and Y.-A. Park, Observations on shelf and subtidal channel flow: implications of sediment dispersal seaward of the Keum River estuary, Korea. Est., Coastal and Shelf Sci., 34, 365-379, 1992.

Zimmerman, J. T. F., The influence of the subaqueous profile on wave induced bottom stress. Netherlands J. Sea Res. 6, 542-549, 1973.

\section{Appendix - List of Symbols}

a tidal amplitude

A cumulative horizontal basin area

A $\quad$ A at $x=L$

$A_{m} \quad$ maximum value of $A$

b width of flat parallel to shoreline

$b_{0} \quad b$ at $x=0$

$b_{\mathrm{L}} \quad b$ at $\mathrm{x}=\mathrm{L}$

B $\quad \mathrm{B}\left(\mathrm{x}_{1}, \mathrm{x}_{2}\right)=\left(\mathrm{b}\left(\mathrm{x}_{1}\right) / \mathrm{b}\left(\mathrm{x}_{2}\right)+1\right) / 2$

$c_{d}$ drag coefficient

$\mathrm{C}_{1,2,3}$ constants

$\mathrm{C}_{\mathrm{g}} \quad$ wind wave group velocity

D energy dissipation by bottom friction

E wave energy density

g acceleration of gravity

h still water depth or local elevation

$\mathrm{h}_{0} \quad \mathrm{~h}$ at $\mathrm{x}=0$

$h_{m} \quad$ maximum value of $h$

$\mathrm{H}$ wave height

$\mathrm{H}_{0} \quad \mathrm{H}$ at $\mathrm{x}=0$ 


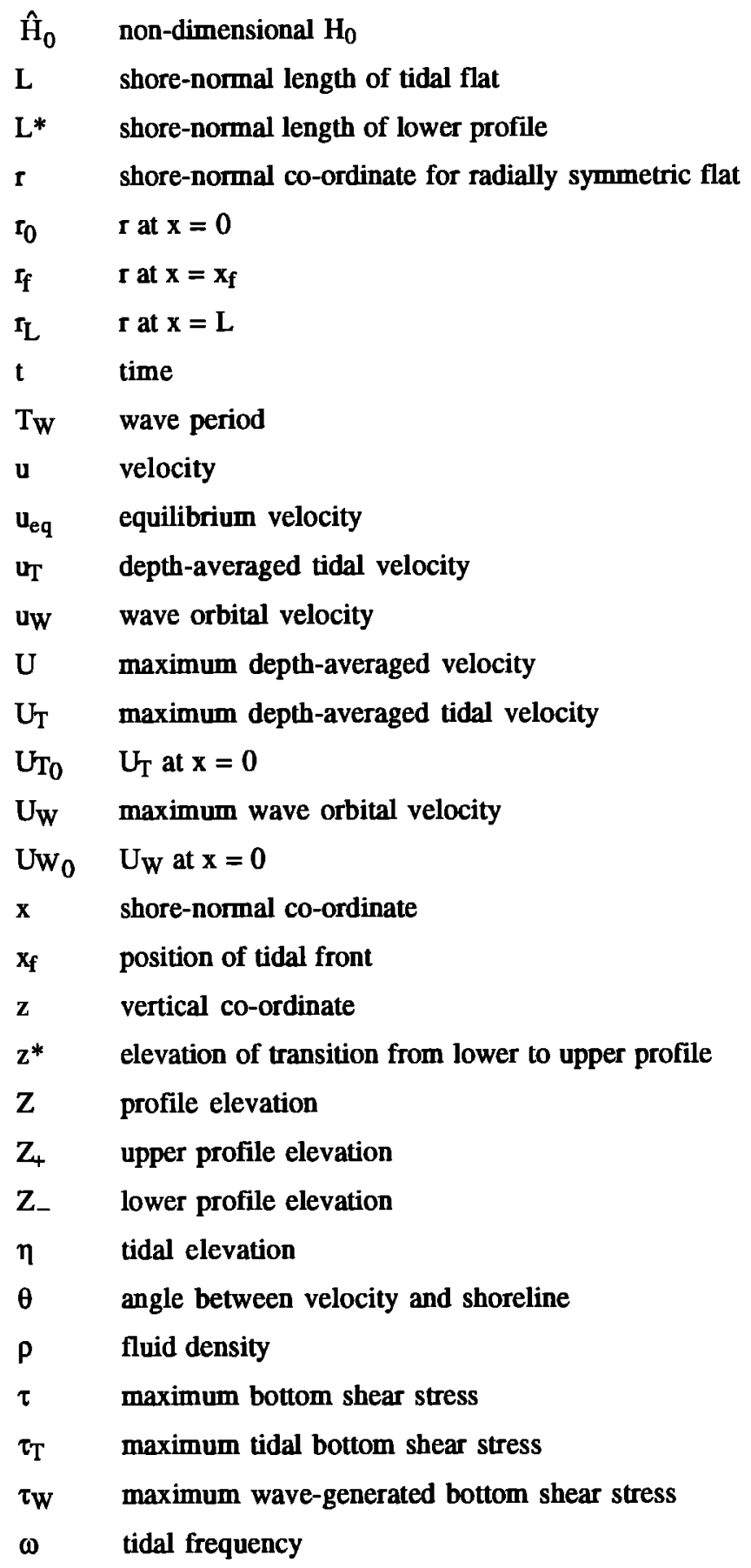

